\title{
Microplastic ingestion in jellyfish Pelagia noctiluca (Forsskal, 1775) in the North Atlantic Ocean
}

Jorge Rapp ${ }^{\mathrm{a}, *}$, Alicia Herrera ${ }^{\mathrm{ac}}$, Daniel R. Bondyale-Juez ${ }^{\mathrm{a}}$, Miguel González-Pleiter $^{\mathrm{b}}$, Stefanie Reinold ${ }^{\mathrm{a}}$, Maite Asensio ${ }^{\mathrm{c}}$, Ico Martínez ${ }^{\mathrm{a}}$ and May Gómez ${ }^{\mathrm{a}}$

\footnotetext{
a Marine Ecophysiology Group (EOMAR), IU- ECOAQUA. Universidad de Las Palmas de Gran Canaria, Campus Universitario de Tafira. Las Palmas de Gran Canaria. Canary Islands, Spain.

b Departamento de Biología, Facultad de Ciencias, Universidad Autónoma de Madrid, Cantoblanco, E28049 Madrid, Spain

c Asociación para la Conservación Medioambiental Latitud Azul. Av Mesa y López 57-15A, Las Palmas de Gran Canaria, Spain.
}

E-mail addresses: jorge.rapp101@alu.ulpgc.es (J. Rapp), alicia.herrera@ulpgc.es (A. Herrera), daniel.bondyale101@alu.ulpgc.es (D.R. Bondyale-Juez), mig.gonzalez@uam.es (M. González-Pleiter)stefanie_reinold@yahoo.de (S. Reinold), maite.asensio@hotmail.com (M. Asensio), ico.martinez@ulpgc.es (I. Martínez), may.gomez@ulpgc.es (M. Gómez).

* Corresponding author. E-mail address: jorge.rapp101@alu.ulpgc.es (J. Rapp)

\begin{abstract}
The presents work is the first study that evidences the ingestion of plastic and microplastics in jellyfish Pelagia noctiluca in the Atlantic Ocean. A bloom of this organism was collected from Gran Canaria island coast. Then, separating umbrella from tentacles, a process of $\mathrm{KOH}$ digestion was carried out to quantify the plastic particles. A $97 \%$ of the individuals analysed had microdebris. The majority were blue and mostly microfibres, mainly composed by cotton. The presence of items in the gastrovascular cavity was confirmed. These results warn about the implications for jellyfish health, the transfer to jellyfish predators, human consumed jellyfish and the transport of carbon and microplastic in the water column.
\end{abstract}

KEY WORDS: microplastic, ingestion, bloom, jellyfish, Pelagia noctiluca 
Marine plastic pollution is becoming a problem of growing concern to the scientific community, environmental policy makers and society. So much so that our age is referred to as the "Plastic Age". Marine plastic debris, microplastics in particular, represent a serious problem because, due to theirs size and associated pollutants, can be ingested by marine organism and pass through the trophic web (Carbery et al., 2018; Gall and Thompson, 2015; Ivar Do Sul and Costa, 2014). The effects they can have on the health of organisms are still unknown. The ingestion of microplastics has been documented in numerous species of marine mammals and birds, fish, mollusk, crustaceans, echinoderms (Derraik, 2002; Fossi et al., 2018; Franzellitti et al., 2019), and in cnidarians too, as corals (Hall et al., 2015) and true jellyfish (Macali et al., 2018).

From Moore et al. (2001), there has been a growing number of works discussing the distribution and abundance of microplastics and its impact on planktonic communities especially in the oceanic surface layers (Cole et al., 2013; Desforges et al., 2015; Sun et al., 2017).The concentration of plastic pollution in oceanic gyres is highest and where the chances of interaction microplastic-organism increase (Botterell et al., 2020; Cózar et al., 2014). Moreover, Choy et al. (2019) have shown that the distribution of plastic extends deeper in the water column possibly further impacting the niche of zooplanktonic communities such as the sometimes overlooked gelatinous zooplankton. Here we studied the impact of microplastics on the scyphozoan jellyfish $P$. noctiluca.

This scyphozoan is an important non selective predator of several types of zooplankton and ichthyoplankton, showing the same nocturnal migration of their preys and playing an important role in the control of marine food webs (Purcell et al., 2007; Rosa et al., 2013; Sabatés et al., 2010). Moreover, this pelagic organism is a holoplanktonic specie, therefore lacks a benthic stage in its life-cycle, characteristic which explains why this jellyfish is widely distributed (Canepa et al., 2014) around all North Atlantic and Mediterranean sea (Licandro et al., 2010). These regions are known for their high concentrations of microplastics contamination, especially in the convective areas (Cózar et al., 2014; Eriksen et al., 2014; Van Sebille, 2015).

The surrounding waters on the eastern margin of the North Atlantic are a hot spot of marine microplastics contamination due to their geolocation (Álvarez-Hernández et al., 2019; Baztán et al., 2014; Herrera et al., 2018a; Herrera et al., 2020; Rapp et al., 2020; Reinold et al., 2020) and a region with occasional blooms of $P$. noctiluca (Rodríguez et al., 2015). This increases the probability of possible interactions between jellyfish and debris.

In this study we investigate the natural $P$. noctiluca-microplastic interaction and its impact during a jellyfish bloom, paying especial attention to ingestion and entanglement of microplastics. 


\section{HERE FIGURE 1}

During the summer of 2019, a bloom of jellyfish occurred in the Gran Canaria island (Canary Islands, Spain) similar to those documented in Rodríguez et al. (2015) for this region. A total of 30 Pelagia noctiluca were collected, floating near the shore of Las Canteras beach $\left(28^{\circ} 7.854^{\prime} \mathrm{N} ; 15^{\circ} 26.775^{\prime} \mathrm{W}\right)$. They were stored separately and frozen at $-20^{\circ} \mathrm{C}$ for later analysis.

In the laboratory, the surface of the jellyfish was carefully rinsed with bidistilled water. Then, the umbrella and tentacles of the jellyfish were analysed separately in order to determine whether the microdebris were within the gastrovascular cavity or adhered to the tentacles. Later, following the protocol proposed by Herrera et al. (2018b), both parts were digested with $\mathrm{KOH}$ at $10 \%$. The digestion took place for 24 hours at $60^{\circ} \mathrm{C}$. Finally, the plastics were analysed under a binocular stereomicroscope (Leica S9i with integrated CMOS camera); differentiating by types (Rezania et al., 2018) and colours.

All necessary measures were taken to avoid airborne fibre contamination (Herrera et al., 2018b; Rapp et al., 2020). All materials were carefully washed with bidistilled water, that samples were processed inside a hood and cotton laboratory coats were used during all steps of the process. Moreover, during the processing, an open petri dish with a wet filter was put to check the airborne contamination inside the fume hood.

To determine the typology of the polymers identified in the organisms, the analysis of the chemical composition of the items found in $30 \%$ of the analyzed jellyfish was carried out (both umbrella and tentacles parts). The chemical composition of all particles was spectrophotometrically analyzed by micro Fourier Transform Infrared Spectroscopy $(\mu F T I R)$, using a Perkin-Elmer Spotlight 200 Spectrum two apparatus with mercury cadmium telluride detector. For it, the analyzed particles were placed on $\mathrm{KBr}$, which was used as a slide, and their spectra were recorded in micro-transmission mode using the following parameters: spot $50 \mu \mathrm{m}, 32$ scans, and spectral range 550-4000 cm -1 with 8 $\mathrm{cm}-1$ resolution. The spectra were compared with Omnic 9 database and with spectra from our own database showing $>70 \%$ matching in all cases, which was considered enough for positive identification of plastic materials.

Based on the whole jellyfish, 29 of the 30 jellyfish assessed had microdebris (Fig. 2). These results show how gelatinous zooplankton is being impacted by this debris, although the specimens did not appear clearly negatively affected by the plastic presence.

The analysis by parts reveals that a greater impact was observed in the tentacles than in the umbrella (Table 1), being the incidence of $86.7 \%$ and $53.3 \%$ respectively (Fig. 2).

\section{HERE FIGURE 2}

\section{HERE TABLE 1}


The tentacles sections of the organisms sampled had an average of $2.47 \pm 2.01$ microplastic items while in the umbrella sections were $1.17 \pm 1.70$. The maximums obtained for each part were high, being 7 in the tentacle sections and 8 in the umbrella sections (Table 1).

The major part of these items were synthetic or semi-synthetic fibres, the most frequent types of microplastics in the marine environments (Browne et al., 2011) and mainly composed of cotton (76\%, Fig. 4), followed by plastic fragments and lines (Fig. 3.a). Moreover the main colour of these items was blue (Fig. 3.b), the most predominant colour for these types of debris (Gago et al., 2018).

\section{HERE FIGURE 3}

On the other hand, taking as a reference the classification provided in González-Pleiter et al. (2020) for the chemical composition of the fibres. The most of the fibres found were cotton (71\%), followed by rayon/viscose fibres (6.45\%). Acrylic, cellophane, cellulose, linen and polypropylene (PP) fibres were also found (Fig. 4). The fragments found were composed of PP and Polyethylene (PE). Demonstrating the artificial origin of the plastics found in the analysed organisms, both synthetic (fibres composed wholly or partly of acrylics, linen and PP), semi-synthetic (fibres composed partly of linen, cellophane and rayon/viscose) and natural (fibres composed wholly or partly of cellulose and cotton) (González-Pleiter et al., 2020).

\section{HERE FIGURE 4}

With the presence of microplastic items after the $\mathrm{KOH}$ digestion in the umbrella sections confirms the presence of debris within the gastrovascular cavity, then, the ingestion of microplastics by jellyfish during the bloom is checked.

The effects these microplastics may have on the health of the organisms are unknown (Botterell et al., 2018). Cole et al. (2013) showed microplastics ingestion in several zooplankton species including gelatinous organisms such as doliolids, but did not confirm the ingestion by hydrozoans. Similarly, Costa et al. (2020), showed some negative effects of ingestion of microplastics polyethylene spheres on the behaviour and health of ephyra stages of the jellyfish Aurelia sp. Hence, ephyra of $P$. noctiluca could also be vulnerable to microplastics ingestion. A negative impact on $P$. noctiluca populations that increased its mortality rate could affect its ecological role and destabilize regional food webs (Doyle et al., 2013; Purcell et al., 2007; Rosa et al., 2013; Sabatés et al., 2010).

A considerable presence of microplastics in P. noctiluca was observed in this study. Based on umbrella microplastics presence, one out of every two jellyfish would have ingested plastic before being sampled, showing a higher percentage of affected jellyfish than the values reported in the Mediterranean sea (Macali et al., 2018). A possible hypothesis for this high incidence is that the area where the jellyfish were collected is a 
closed bay that concentrates a large amount of microplastics and has a high microplastic/zooplankton ratio (Herrera et al., 2020). In addition, other studies in the region show a high percentage of microplastic ingestion in fish (Herrera et al., 2019).

As discussed in Macali et al. (2018), this could be an important entry pathway of microplastics debris to the trophic webs. Jellyfish are prey for a wide variety of predators (Pauly et al., 2008; Milisenda et al., 2014) including humans (Brotz and Pauly, 2017).. For that, jellyfish act as a vector for plastic ingestion to selective feeders (Setälä et al., 2018), especially routine feeders like leatherback sea turtles. Heaslip et al. (2012) shown that Dermochelys coriacea consume $73 \%$ of jellyfish of its body mass per day. On the other hand, comercial jellyfish fisheries for human consumption should be concern about the vulnerability of jellyfish to microplastics contamination. Research on microplastics contamination in the order Rhizostomeae, the main order of commercially harvested jellyfish, and in other areas of the planet should be conduct.

Furthermore, taking into account the biological characteristics of these organisms, their wide dispersion in the oceans and their high interaction with microplastics, as observed in this study, jellyfish could be a clear bioindicator of plastic contamination. This same approach is taken into account in Macali and Bergami (2020), who propose jellyfish as invertebrate bio-indicators to monitor plastic contamination in pelagic waters, along with associated organisms in the food chain, recommending their inclusion in future monitoring studies.

Other gelatinous zooplankton species have been shown to be affected by microplastics ingestion; due to their filter feeding nature (Choy et al., 2019; Cole et al., 2013; Katija et al., 2017; Wieczorek et al., 2019). Apart from their trophic role, gelatinous zooplankton play an important function in carbon sequestration (Doyle et al., 2013). Wieczorek et al. (2019) tested and suggested that salp faecal pellets containing microplastics will decrease their sinking speed. In the case of jellyfish their carcasses provide a significant source of carbon input to the seabed (Lebrato et al., 2012; Sweetman and Chapman, 2015). We consider that since jellyfish are exposed to, and ingest microplastics the effect on the sinking of jellyfish should be assessed. The large bloom formation by several jellyfish species could either be experiencing a decrease in sinking speed as observed by Wieczorek et al. (2019) or serve as source of plastic sinking as suggested by Choy et al. (2019). The analysis of seabed sunk jellyfish carcasses could shed some light on this route of plastic transport to deeper layers.

The impact on the well-being of organism that ingests microplastics requires further study. But this study confirms a common ingestion of microplastics by $P$. noctiluca suggesting the possible ingestion by other jellyfish. This may have implications on plastic ingestion by jellyfish predators, on plastic contamination on harvested jellyfish species for human consumption, and on carbon transport and plastic sinking by large jellyfish blooms exposed to widely distributed ocean microplastics.

\section{ACKNOWLEDGEMENTS}

This work was supported by the projects IMPLAMAC (MAC2/1.1a/265) Interreg MAC (European Fund to Regional Development, Macaronesian Cooperation) and INDICIT II (European Commission, MSFD- SECOND CYCLE: IMPLEMENTATION OF THE NEW GES DECISION AND PROGRAMMES OF MEASURES). 


\section{TABLE}

Table 1. Statistical analysis of the abundance of microdebris found in tentacles and bell of the jellyfish samples.

Number of microdebris items found in P. noctiluca $(\mathrm{n}=$ 30)

\begin{tabular}{llll}
\hline Part of jellyfish & Mean \pm Sd & Max & Min \\
\hline Tentacle & $2.47 \pm 2.01$ & 7 & 0 \\
Umbrella & $1.17 \pm 1.70$ & 8 & 0 \\
\hline
\end{tabular}

Sd: Standard deviation; Max: maximum; Min: mininmum.

\section{FIGURES}

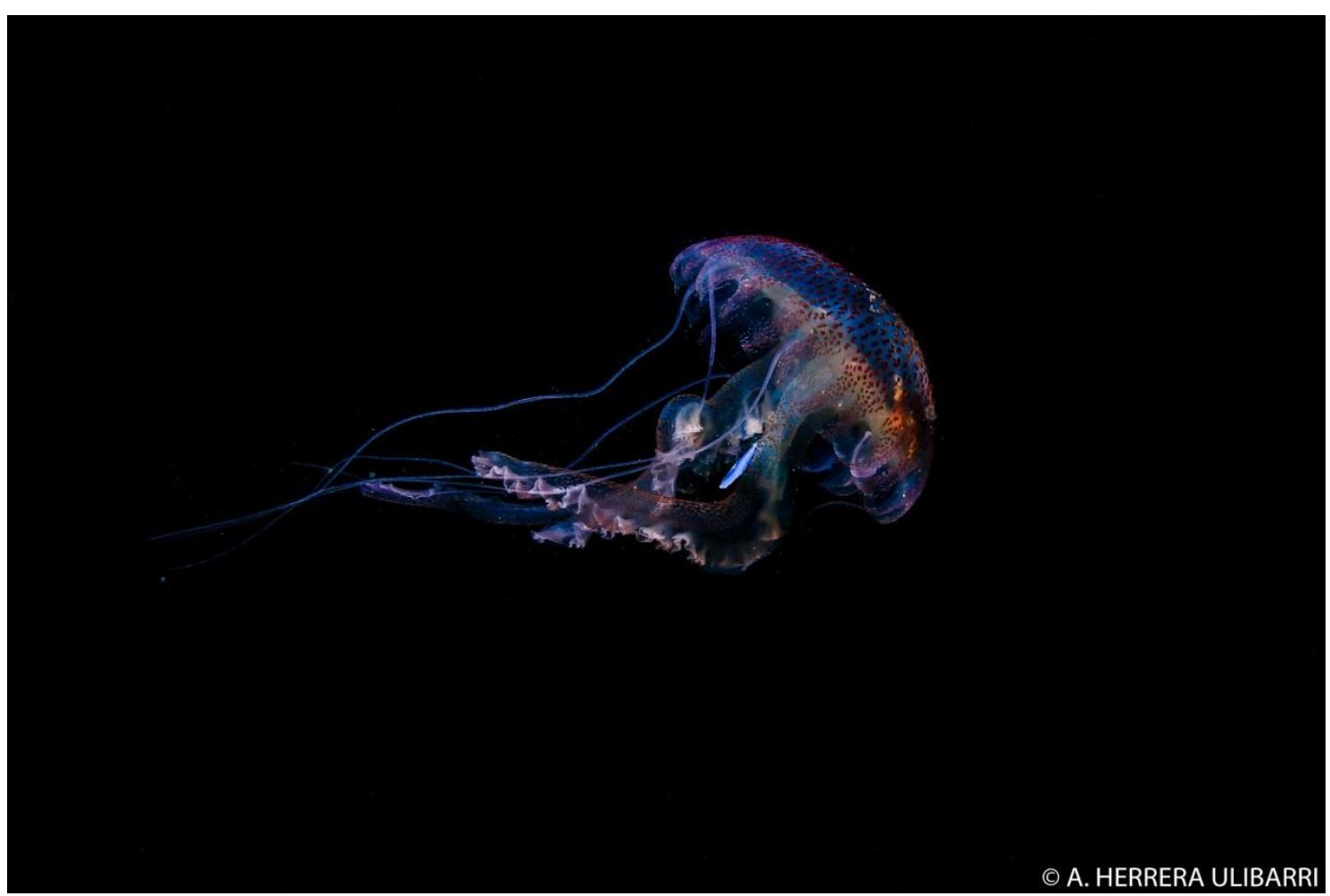

Fig. 1. Photograph taken by Alicia Herrera of a Pelagia noctiluca jellyfish on the coast of Gran Canaria, Canary Islands (Spain). The organism has a blue plastic particle between its tentacles. 


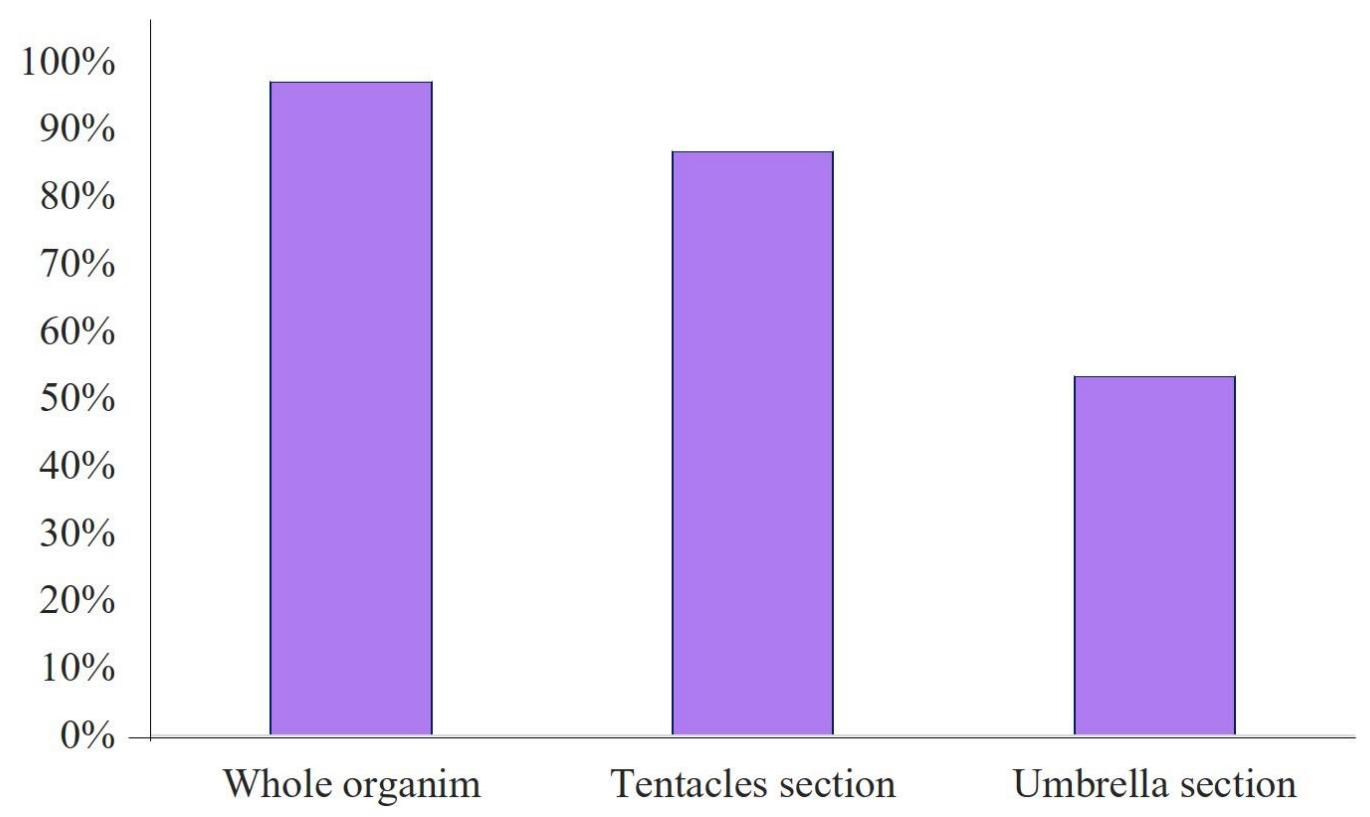

Fig. 2. Percentage of microdebris presents in the 30 caught $P$. noctiluca.
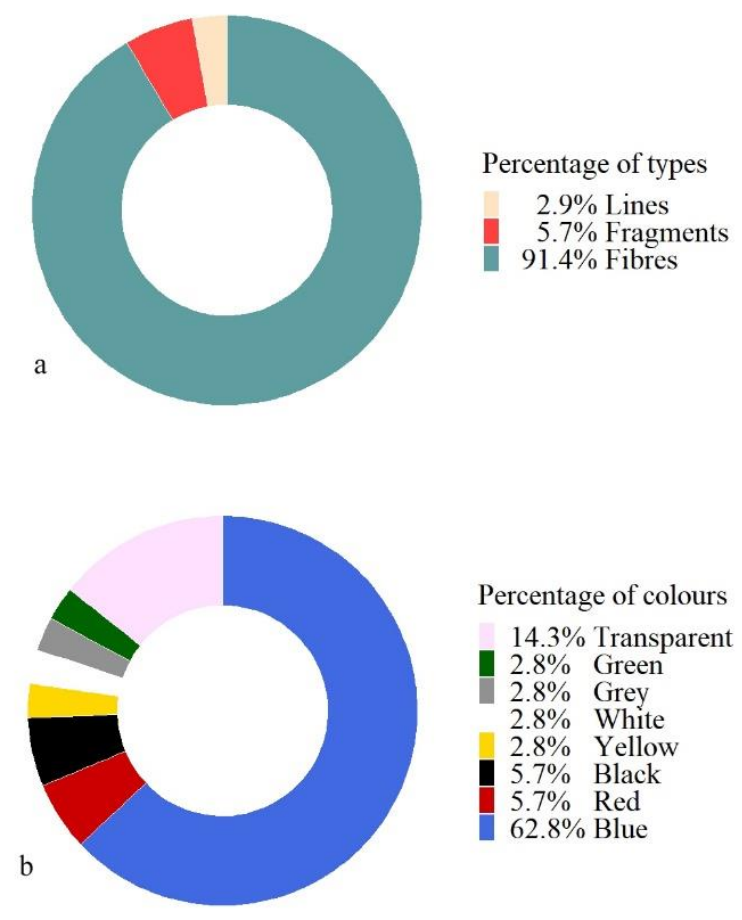

Fig. 3. Percentage of types (a) and colours (b) of the microdebris found in P. noctiluca samples gastrovascular cavity. 

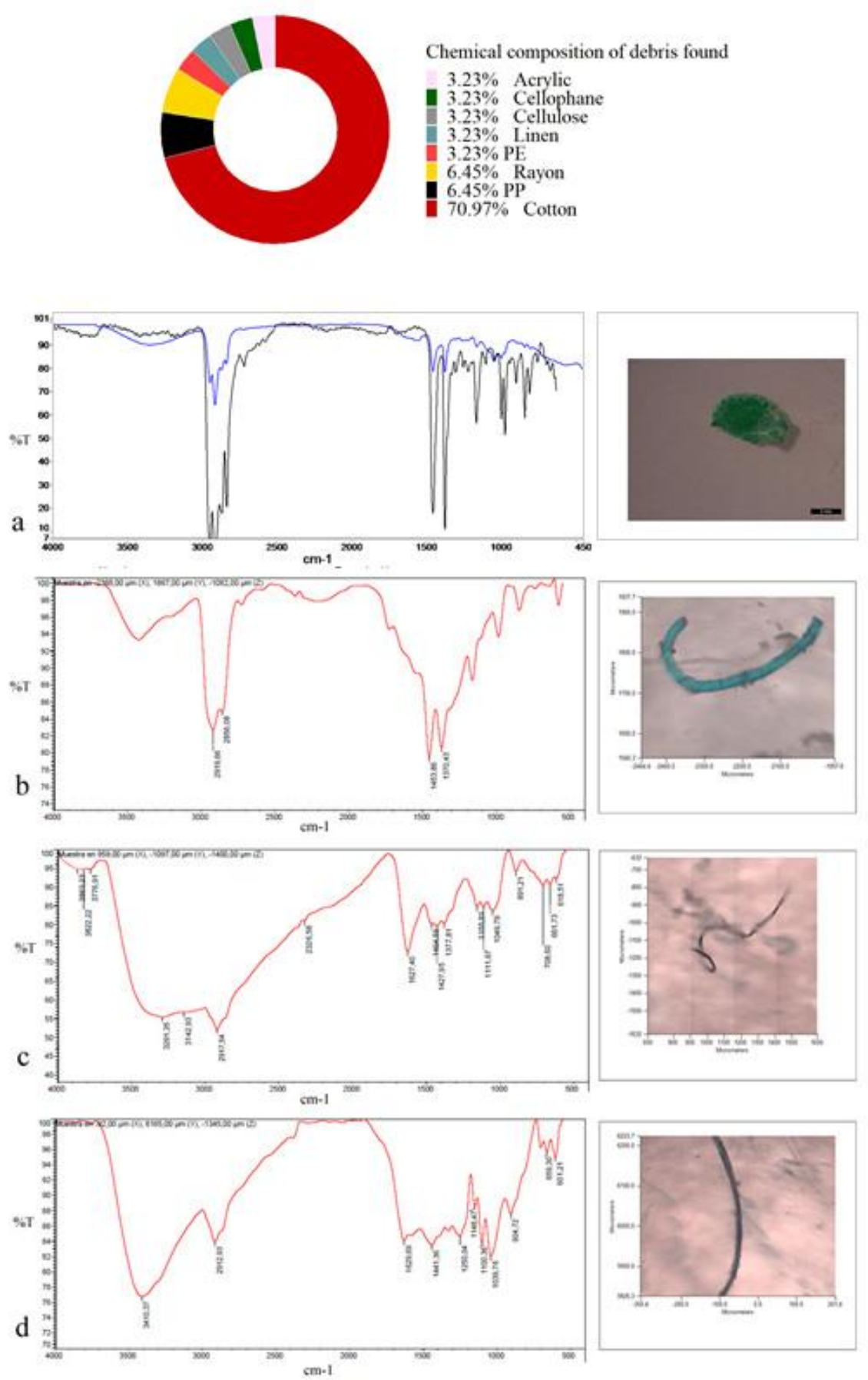

Fig. 4. Chemical composition of 21 microdebris found on a $30 \%$ of jellyfish. Subsamples analysed by $\mu$ FITR polymer classification used according to González-Pleiter et al., 2020. $\mu$ FTIR spectra and microphotography of (a) PP Green fragment (black line), (b) Blue synthetic PP fibre, (c) Semi-synthetic rayon/viscose fibre (d) Semi-synthetic cotton-linen fibre. 


\section{REFERENCES}

Álvarez-hernández, C., Cairós, C., López-darias, J., Mazzetti, E., 2019. Microplastic debris in beaches of Tenerife ( Canary Islands , Spain ). Mar. Pollut. Bull. 146, 2632. https://doi.org/10.1016/j.marpolbul.2019.05.064

Baztán, J., Carrasco, A., Chouinard, O., Cleaud, M., Gabaldon Jesús, E., Huck, T., Jaffrès, L., Jorgensen, B., Miguelez, A., Paillard, C., Vanderlinden, J., 2014. Protected areas in the Atlantic facing the hazards of micro-plastic pollution : First diagnosis of three islands in the Canary Current. Mar. Pollut. Bull. 80, 302-311. https://doi.org/10.1016/j.marpolbul.2013.12.052

Botterell, Z.L.R., Beaumont, N., Dorrington, T., Steinke, M., Thompson, R.C., Lindeque, P.K., 2020. Bioavailability and effects of microplastics on marine zooplankton: Environ. Pollut. 245, 98-110. https://doi.org/10.1016/j.envpol.2018.10.065

Brotz, L., \& Pauly, D. (2017). Studying jellyfish fisheries: toward accurate national catch reports and appropriate methods for stock assessments. Jellyfish: ecology, distribution patterns and human interactions. Nova Publishers, New York, 313-329.

Browne, M.A., Crump, P., Niven, S.J., Teuten, E., Tonkin, A., Galloway, T., Thompson, R., 2011. Accumulation of microplastic on shorelines woldwide: Sources and sinks. Environ. Sci. Technol. 45, 9175-9179. https://doi.org/10.1021/es201811s

Canepa, A., Fuentes, V., Sabatés, A., Piraino, S., Boero, F., Gili, J.-M., 2014. Pelagia noctiluca in the Mediterranean Sea, in: A. Pitt, K. (Australian R.I. and G. th S. of E., H. Lucas, C. (Cathy H.L.N.O.C.S. (Eds.), Jellyfish Blooms. https://doi.org/10.1007/978-94-007-7015-7

Carbery, M., O'Connor, W., Palanisami, T., 2018. Trophic transfer of microplastics and mixed contaminants in the marine food web and implications for human health. Environ. Int. 115, 400-409. https://doi.org/10.1016/j.envint.2018.03.007

Choy, C.A., Robison, B.H., Gagne, T.O., Erwin, B., Firl, E., Halden, R.U., Hamilton, J.A., Katija, K., Lisin, S.E., Rolsky, C., Houtan, K.S. Van, 2019. The vertical distribution and biological transport of marine microplastics across the epipelagic and mesopelagic water column. Sci. Rep. 1-9. https://doi.org/10.1038/s41598-01944117-2

Cole, M., Lindeque, P., Fileman, E., Halsband, C., Goodhead, R., Moger, J., Galloway, T.S., 2013. Microplastic Ingestion by Zooplankton. https://doi.org/10.1021/es400663f

Costa, E., Gambardella, C., Piazza, V., Vassalli, M., Sbrana, F., Lavorano, S., Garaventa, F., Faimali, M., 2020. Ecotoxicology and Environmental Safety Microplastics ingestion in the ephyra stage of Aurelia sp . triggers acute and behavioral responses. $\begin{array}{llll}\text { Ecotoxicol. } & \text { Environ. } & \text { Saf. } & 189983 .\end{array}$ https://doi.org/10.1016/j.ecoenv.2019.109983

Cózar, A., Echevarría, F., González-Gordillo, J.I., Irigoien, X., Ubeda, B., HernándezLeón, S., Palma, A.T., Navarro, S., García-de-Lomas, J., Ruiz, A., Fernández-dePuelles, M.L., Duarte, C.M., 2014. Plastic debris in the open ocean. Proc. Natl. Acad. Sci. U. S. A. 111, 10239-10244. https://doi.org/10.1073/pnas.1314705111

Derraik, J.G.B., 2002. The pollution of the marine environment by plastic debris: A 
review. Mar. Pollut. Bull. 44, 842-852. https://doi.org/10.1016/S0025$326 \mathrm{X}(02) 00220-5$

Desforges, J.W., Galbraith, M., Ross, P.S., 2015. Ingestion of Microplastics by Zooplankton in the Northeast Pacific Ocean. Arch. Environ. Contam. Toxicol. 69, 320-330. https://doi.org/10.1007/s00244-015-0172-5

Doyle, T.K., Hays, G.C., Harrod, C., Houghton, J.D.R., 2013. Ecological and Societal Benefits of Jellyfish 105-127. https://doi.org/10.1007/978-94-007-7015-7

Eriksen, M., Lebreton, L.C.M., Carson, H.S., Thiel, M., Moore, C.J., Borerro, J.C., Galgani, F., Ryan, P.G., Reisser, J., 2014. Plastic Pollution in the World's Oceans: More than 5 Trillion Plastic Pieces Weighing over 250,000 Tons Afloat at Sea. PLoS One 9, 1-15. https://doi.org/10.1371/journal.pone.0111913

Fossi, M.C., Pedà, C., Compa, M., Tsangaris, C., Alomar, C., Claro, F., Ioakeimidis, C., Galgani, F., Hema, T., Deudero, S., Romeo, T., Battaglia, P., Andaloro, F., Caliani, I., Casini, S., Panti, C., Baini, M., 2018. Bioindicators for monitoring marine litter ingestion and its impacts on Mediterranean biodiversity * 237. https://doi.org/10.1016/j.envpol.2017.11.019

Franzellitti, S., Canesi, L., Auguste, M., Wathsala, R.H.G.R., Fabbri, E., 2019. Microplastic exposure and effects in aquatic organisms : A physiological perspective 68, 37-51. https://doi.org/10.1016/j.etap.2019.03.009

Gago, J., Carretero, O., Filgueiras, A. V., Viñas, L., 2018. Synthetic microfibers in the marine environment: A review on their occurrence in seawater and sediments. Mar. Pollut. Bull. 127, 365-376. https://doi.org/10.1016/j.marpolbul.2017.11.070

Gall, S.C., Thompson, R.C., 2015. The impact of debris on marine life. Mar. Pollut. Bull. 92, 170-179. https://doi.org/10.1016/j.marpolbul.2014.12.041

González-Pleiter, M., Edo, C., Aguilera, Á., Viúdez-Moreiras, D., Pulido-Reyes, G., González-Toril, E. \& Rosal, R. (2020). Occurrence and transport of microplastics sampled within and above the planetary boundary layer. Science of The Total Environment, 143213.

Hall, N.M., Berry, K.L.E., Rintoul, L., Hoogenboom, M.O., 2015. Microplastic ingestion by scleractinian corals. Mar. Biol. 725-732. https://doi.org/10.1007/s00227-0152619-7

Herrera, A, Asensio, M., Martínez, I., Santana, A., Packard, T., Gómez, M., 2018. Microplastic and tar pollution on three Canary Islands beaches : An annual study. Mar. Pollut. Bull. 129, 494-502. https://doi.org/10.1016/j.marpolbul.2017.10.020

Herrera, Alicia, Garrido-amador, P., Martínez, I., Samper, M.D., López-martínez, J., Gómez, M., Packard, T.T., 2018. Novel methodology to isolate microplastics from vegetal-rich samples. Mar. Pollut. Bull. 129, 61-69. https://doi.org/10.1016/j.marpolbul.2018.02.015

Herrera, A., Raymond, E., Martínez, I., Álvarez, S., Canning-clode, J., Gestoso, I., 2020. First evaluation of neustonic microplastics in the Macaronesian region, NE Atlantic. Mar. Pollut. Bull. 153, 110999. https://doi.org/10.1016/j.marpolbul.2020.110999

Herrera, A., Stindlová, A., Martínez, I., Rapp, J., Romero-Kutzner, V., Samper, M.D., Montoto, T., Aguiar-González, B., Packard, T., Gómez, M., 2019. Microplastic 
ingestion by Atlantic chub mackerel (Scomber colias) in the Canary Islands coast. Mar. Pollut. Bull. 139, 127-135. https://doi.org/10.1016/j.marpolbul.2018.12.022

Herrera, A., Raymond, E., Martínez, I., Álvarez, S., Canning-Clode, J., Gestoso, I., \& Gómez, M, 2020. First evaluation of neustonic microplastics in the Macaronesian region, NE Atlantic. Marine Pollution Bulletin, 153, 110999.

Ivar Do Sul, J. a., Costa, M.F., 2014. The present and future of microplastic pollution in the marine environment. Environ. Pollut. 185, 352-364. https://doi.org/10.1016/j.envpol.2013.10.036

Katija, K., Choy, C. A., Sherlock, R. E., Sherman, A. D., \& Robison, B. H. (2017). From the surface to the seafloor: How giant larvaceans transport microplastics into the deep sea. Science advances, 3(8), e1700715.

Lebrato, M., Pitt, K.A., Sweetman, A.K., Jones, D.O.B., Cartes, J.E., Oschlies, A., Condon, R.H., Carlos, J., Adler, L., Gaillard, C., Lloris, D., Billett, D.S.M., 2012. Jelly-falls historic and recent observations: a review to drive future research directions 227-245. https://doi.org/10.1007/s10750-012-1046-8

Licandro, P., Conway, D. V. P., Daly Yahia, M. N., Fernandez de Puelles, M. L., Gasparini, S., Hecq, J. H., ... \& Kirby, R. R. (2010). A blooming jellyfish in the northeast Atlantic and Mediterranean. Biology letters, 6(5), 688-691.

Macali, A., Semenov, A., Venuti, V., Crupi, V., Amico, F.D., Rossi, B., Corsi, I., 2018. Episodic records of jellyfish ingestion of plastic items reveal a novel pathway for trophic transference of marine litter. Mar. Biol. 1-5. https://doi.org/10.1038/s41598018-24427-7

Macali, A., \& Bergami, E. (2020). Jellyfish as innovative bioindicator for plastic pollution. Ecological Indicators, 115, 106375.

Moore, C.J., Moore, S.L., Leecaster, M.K., Weisberg, S.B., 2001. A comparison of plastic and plankton in the North Pacific Central Gyre. Mar. Pollut. Bull. 42, 1297-1300. https://doi.org/10.1016/S0025-326X(01)00114-X

Pauly, D., Graham, Æ.W., Libralato, S., Morissette, Æ.L., Palomares, M.L.D., 2008. Jellyfish in ecosystems, online databases, and ecosystem models 67-85. https://doi.org/10.1007/s10750-008-9583-X

Purcell, J.E., Uye, S., Lo, W., 2007. Anthropogenic causes of jellyfish blooms and their direct consequences for humans: a review 350, 153-174. https://doi.org/10.3354/meps07093

Rapp, J., Herrera, A., Martinez, I., Raymond, E., Santana, Á., Gómez, M., 2020. Study of plastic pollution and its potential sources on Gran Canaria Island beaches ( Canary Islands , Spain ). Mar. Pollut. Bull. 153, 110967. https://doi.org/10.1016/j.marpolbul.2020.110967

Reinold, S., Herrera, A., Hernández-gonzález, C., Gómez, M., 2020. Plastic pollution on eight beaches of Tenerife ( Canary Islands, Spain ): An annual study. Mar. Pollut. Bull. 151, 110847. https://doi.org/10.1016/j.marpolbul.2019.110847

Rezania, S., Park, J., Fadhil, M., Mat, S., Talaiekhozani, A., Kumar, K., Kamyab, H., 2018. Microplastics pollution in different aquatic environments and biota: A review of recent studies 133, 191-208. https://doi.org/10.1016/j.marpolbul.2018.05.022 
Rodríguez, G., Clarindo, G., Mcknight, L., 2015. Jellyfish outbreaks in coastal city beaches from a management perspective. https://doi.org/10.2495/CC150231

Rosa, S., Pansera, M., Granata, A., Guglielmo, L., 2013. Interannual variability , growth , reproduction and feeding of Pelagia noctiluca (Cnidaria : Scyphozoa) in the Straits of Messina ( Central Mediterranean Sea ): Linkages with temperature and diet. J. Mar. Syst. 111-112, 97-107. https://doi.org/10.1016/j.jmarsys.2012.10.001

Sabatés, A., Fuentes, V., Atienza, D., Purcell, J.E., 2010. Planktonic cnidarian distribution and feeding of Pelagia nociluca in the NW Mediterranean Sea. Hydrobiologia. https://doi.org/10.1007/s10750-010-0221-z

Setälä, O., Lehtiniemi, M., Coppock, R., Cole, M., 2018. Microplastics in Marine Food Webs 339-363. https://doi.org/10.1016/B978-0-12-813747-5.00011-4

Sun, X., Li, Q., Zhu, M., Liang, J., Zheng, S., Zhao, Y., 2016. Ingestion of microplastics by natural zooplankton groups in the northern South China Sea. Mar. Pollut. Bull. 115, 217-224. https://doi.org/10.1016/j.marpolbul.2016.12.004

Sweetman, A.K., Chapman, A., 2015. First assessment of flux rates of jellyfish carcasses ( jelly-falls ) to the benthos reveals the importance of gelatinous material for biological C-cycling in jellyfish-dominated ecosystems 2, 1-7. https://doi.org/10.3389/fmars.2015.00047

Van Sebille, E., 2015. The oceans' accumulating plastic garbage. Phys. Today 68, 60-61. https://doi.org/10.1063/PT.3.2697

Wieczorek, A.M., Croot, P.L., Lombard, F., Sheahan, J.N., Doyle, T.K., 2019. Microplastic Ingestion by Gelatinous Zooplankton May Lower Efficiency of the Biological Pump. Environ. Sci. Technol. 53, 5387-5395. https://doi.org/10.1021/acs.est.8b07174 